\title{
Appreciation
}

\section{Simon Dack}

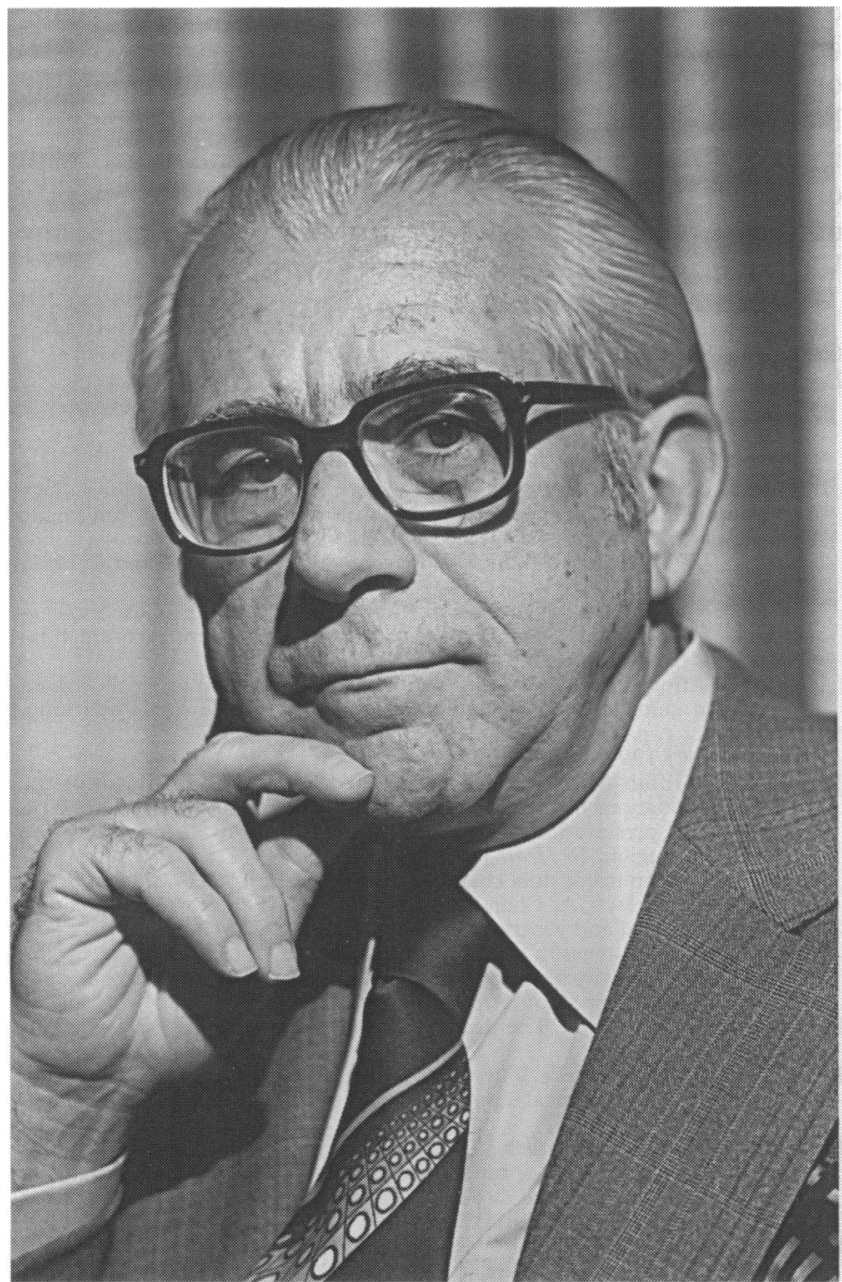

We, associated with the British Heart fournal, share in the sadness of so many on the death of Simon Dack. He was 85 and had been troubled for some years by severe cardiac problems, but with his characteristic tenacity he overcame them until 7 February 1994, when he died peacefully. This was just one month before he was due to receive the Distinguished Service Award of the American College of Cardiology. We write of him as editors, having been closely linked with him over the years, but would like our note to make others aware of the wider dimensions of the man and the physician. His life had been linked with Mount Sinai Hospital since he graduated from New York Medical College in 1932. The lustre of his editorial career may have distracted attention from his abilities as an excellent clinical investigator whose range was wide. Even before the Second World War he had made important contributions to several topics ranging from heart failure to the introduction into clinical use of exercise electrocardiography.

Soon after it was established he strengthened the American College of Cardiology during his presidency in 1956 and he was the first editor of the American fournal of Cardiology in 1958. In 1982 the College started its own journal and two of us were privileged to be witnesses to the decision and to see him start the fournal of the American College of Cardiology in 1983. He handed over the editorship to Bill Parmley in 1992. But this was not the end of his links, for Dr Parmley enlisted him as the outside consultant editor for articles from the Mount Sinai Hospital and he carried on with this almost to the end.

Simon Dack made us all most welcome at the annual editorial meetings of his journal, held at the time of the American College of Cardiology Annual Scientific Sessions. We shared thoughts and he always wanted the current editor of the British Heart fournal to say a few words on how we saw a particular problem. We in turn learnt that we faced the same problems and shared successes: we were always able to use his wisdom to our advantage and were always led to believe that some of our contributions were correspondingly helpful. Our journals have never been rivals but have similar objectives. The ability to carry out our work harmoniously with the opportunity to enquire of each other about methods and presentation is something that we have always appreciated. Simon Dack was the editor personified: he read the papers submitted, and those that were accepted he read very closely indeed. He was an expert copy editor whose ability to seek out the nuggets hidden within excess verbiage was legendary. Authors who saw in proof the shorter and clearer version of their text were indebted to him for this fine talent.

Add to all this his personal kindness and gentle humour, and we hope that all will see why we wish to commemorate the person, career, and editorship of Simon Dack in the British Heart fournal. We, as well as our profession, have lost a colleague who personified clinical excellence and integrity, as well as a natural talent for seeking out and publishing the best in the journals he edited.

DENNIS M KRIKLER $M$ J DAVIES 